\title{
Comparative Study for the Identification of Myocardial Ischemia by Contrast Ventriculography under the Effect of Isosorbide Mononitrate and by Perfusional Myocardial Scintigraphy in Patients with Ischemic Heart Disease
}

\author{
Waldomiro Carlos Manfroi, Roberto Ludwig, Luciana Schmidt Kirschnick, Josiane Souza, \\ Letícia Weiss Ribeiro, Karen Ordovás, Cristiane Leitão, Rosana Cruz, Rafael Candiago
}

\author{
Porto Alegre, RS - Brazil
}

\begin{abstract}
Objective - To evaluate and compare the usefulness of cineventriculographies, before and after nitrate use, to technetium-99m sestamibi scintigraphy for the identification of myocardial ischemia.
\end{abstract}

Methods - Twenty-six patients were studied at basal conditions and 5 minutes after intravenous administration of isosorbide mononitrate $(0.3 \mathrm{mg} / \mathrm{kg})$, to evaluate the performance and regional wall motion of the left ventricle $(L V)$. The results were compared to those obtained with technetium-99m sestamibi scintigraphy.

Results - Before nitrate, contrast ventriculography identified 30 normal segments, 62 hypokinetic segments, 28 dyskinetic segments, and 14 akinetic segments. After drug administration, 99 segments were normal, 11 hypokinetic, 11 dyskinetic, and 13 akinetic. Myocardial scintigraphy revealed 110 ischemic segments and 18 fibrotic segments $(p<0.005)$. After drug administration, the ventriculography showed increase in the velocity of circumferential fiber shortening ( $p=0.0142$ ), the ejection fraction ( $p=0.0462)$, decrease in the end-systolic volume $(p=0.0031)$ and no change in end-diastolic volume.

Conclusion - Contrast ventriculography using nitrate proved to be similar to perfusional myocardial scintigraphy in the identification of myocardial ischemia.

Keywords: myocardial ischemia, myocardial scintigraphy, contrast ventriculography

Faculdade de Medicina da Universidade Federal do Rio Grande do Sul - Porto Alegre Mailing address: Waldomiro Carlos Manfroi - Rua Ramiro Barcelos, 2350 - S/206 - 90035-003 - Porto Alegre, RS - Brazil
Studies performed in research laboratories causing acute occlusion of one branch of the coronary arterial tree have contributed decisively to increase the knowledge of the pathophysiology of myocardial infarction (MI). The time course of coronary occlusion necessary to produce ischemia signs reduction of myocardial contractility, and signs of definite functional loss of an impaired area have been identified ${ }^{1,2}$. Other studies have shown that changes in myocardial function were reversible as long as the coronary flow was reestablished in time. In these studies, it was also possible to demonstrate that the period of time necessary for recovery was proportional to the period of time of coronary occlusion ${ }^{3,4}$.

This new knowledge allowed the identification in the evolutional phase of MI of necrotic and ischemic areas. Applied to human pathophysiology, it has allowed the introduction of new pharmacological therapeutic procedures and mechanical assistance with the purpose of reversing ischemia and reducing the infarcted are $\mathrm{a}^{5,6}$.

The introduction of percutaneous transluminal coronary angioplasty (PTCA), initially for the treatment of angina pectoris ${ }^{7}$, and later as a method for recovering ischemic areas in patients with $\mathrm{MI}^{8}$, had its indication based on these pathophysiological principles. Its therapeutical success depended on invasive and non-invasive laboratory methods, which were increasingly more reliable for the identification of myocardial ischemia, and also on the definition of improved therapeutic management.

During the 1970s, after several clinical and experimental studies proved that nitroglycerin improved coronary flow to ischemic areas, the nitrates began to be used during hemodynamic and cineangiocardiographic studies enabling the distinction between fibrotic and ischemic areas, through the analysis of two ventriculographies, one before and the other after drug administration ${ }^{9-13}$. Although efficient, 
this method was not kept as part of the diagnostic routine, being replaced by other non-invasive investigation procedures. Among the procedures used with growing frequency are those that show myocardial perfusion by imaging, such as perfusional myocardial scintigraphy, radionuclide ventriculography, positron emission tomography, stress echocardiography and Holter monitoring ${ }^{14-24}$.

Technetium-99m (Tc-99m) sestamibi scintigraphy has been used for the detection of myocardial ischemia and cellular viability. Carvalho et $\mathrm{al}^{25}$ showed that the intracellular concentration of the isotope occurs by passive diffusion between the plasma and the mitocondria, due to the negative charges across the membrane.

Although the literature shows the superiority of thallium-201 in relation to Tc-99m sestamibi in the identification of viable myocardium, the sensitivity and specificity of the markers are superimposable in the detection of myocardial ischemia in clinical practice. The physical characteristics of Tc-99m (photopeak of $140 \mathrm{keV}$, half-life of 6 hours) allow better tomographic imaging (SPECT - single photon emission computed tomography).

Coronary angiography is considered the gold standard for the diagnosis of atherosclerotic ischemic heart disease. However, it is not capable of identifying the presence or extension of myocardial ischemia during stress, such as physical exercise or pharmacological stimulis. The experience obtained over the years has shown that the comparison of regional wall motion and performance of the left ventricle (LV) by means of two ventriculographies, one before and the other after the sublingual administration of nitrates, is a useful method for identifying myocardial ischemia ${ }^{10-13}$. Recently, with the use of intravenous injection of isosorbide mononitrate, it has been possible to demonstrate that the drug improves the regional wall motion of almost all the hypokinetic segments, the majority of the dyskinetic segments, and does not improve the motility of akinetic segments ${ }^{26}$.

Considering that coronary angiography and ventriculography are essential for the anatomical and functional diagnosis of coronary circulation, if the method shows sensitivity equivalent to that obtained by myocardial scintigraphy, the identification of ischemic myocardium during catheterization saves time and money in the determination of therapeutical management in some emergencies.

This is why we undertook this study. Our aim was to analyze the possibility of identifying the ischemic myocardial segments of LV visualized by myocardial Tc-99m sestamibi scintigraphy by using two ventriculographies, one before and another after the intravenous administration of nitrate. We also compared the sensitivity and specificity of the two methods for the detection of myocardial ischemia.

\section{Methods}

This study was carried out at the catheterization laboratory and at the Nuclear Medicine Unit of the Hospital de Clínicas de Porto Alegre, School of Medicine of the Universidade Federal do Rio Grande do Sul. The analysis comprised twenty-six patients of both sexes, with and without previous MI, referred for cardiac catheterization and coronary angiography due to symptomatic ischemic heart disease, documented by non-invasive methods. Diabetic patients, those with valvular heart disease alone or associated with myocardial hypertrophy, and those who could not discontinue the use of nitrates 24 hours prior to any of the procedures were excluded.

After being informed about the nature of the procedure, its risks, the reason for the investigation, and its advantages in regard to the best therapeutical choice, the patients signed a consent form for the procedure and research. This form explained that during the routine diagnostic procedure, two ventriculographies would be performed, one before and another after the intravenous administration of isosorbide mononitrate $(0.3 \mathrm{mg} / \mathrm{kg})$, and that the procedure would be useful in choosing the therapeutical management to be adopted following the examination. It also explained that the drug used was similar to the one administered sublingually to relieve angina pectoris. It was also written in the consent form that this drug had already been used in 108 patients in the same laboratory, and none of them experienced severe headache, hypotension, or allergic reaction. On the day of the examination, the patients were admitted to the Pre-Catheterization Unit, where they were interviewed and assessed by a medical resident and a research associate, through a specifically explained protocol, which allowed the analysis of multiple other variables related to ischemic heart disease.

The hemodynamic and cineangiocardiographic procedure, always performed by the research coordinator, comprised left cardiac catheterization through dissection of the right brachial artery at the cubital fossa or through a puncture of the femoral artery at the right inguinal region, under local anesthesia with lidocaine $2 \%$.

Initially, the pressures in the aorta and in the LV were measured. A contrast ventriculography in right anterior oblique (RAO) view at $35^{\circ}$ was then performed with the injection of $35 \mathrm{ml}$ of the contrast medium meglumine amidotrizoate (Urografina 370). This was achieved by means of Contract III injector, at a speed of $15 \mathrm{ml} / \mathrm{s}$, through a Lehmann or Pigtail catheter, according to the procedure's programming. Then the patient remained at rest and the pressures in the aorta and in the LV were continuously monitored until they reached the conditions observed prior to the ventriculography. At this time, isosorbide mononitrate was intravenously injected at a dose of $0.3 \mathrm{mg} / \mathrm{kg}$, for $30 \mathrm{~s}$. Five minutes after the infusion, the pressures in the aorta and in the LV were measured again and a new contrast ventriculography, at the same projection, was performed. The procedure continued with the selective study of the coronary arteries according to the techniques of Sones ${ }^{27}$ or Judkins ${ }^{28}$, according to established planning for the procedure.

Through the analysis of contrast ventriculography, the following variables were calculated: end-diastolic (EDV) and 
end-systolic (ESV) ventricular volumes; LV ejection fraction (EF); mean velocity of circumferential fiber shortening (CFS); and the percentage of shortening of the cardiac hemiaxes (R1R6, R2R5, andR3R4). This was performed through the use of already established methods ${ }^{29-31}$. The alterations of the segmentary motility observed before and after the use of the drug were made according to Herman et al. ${ }^{32}$.

The change in regional wall motion observed by contrast ventriculography before and after the use of the drug were compared to the findings of the scintigraphy. SPECT was always performed by a specialist and a two-day protocol was used, with an interval of 24 hours between the stress and rest exams. The stress consisted of an exercise test on bicycle ergometrer and administration of 20-25 mCi of Tc-99m sestamibi at the peak of the exercise (heart rate $>85 \%$ of the expected). Another type of stress applied was the pharmacological stimulus with intravenous infusion of dipyridamole $(0.56 \mathrm{mg} / \mathrm{kg})$, for 4 minutes, and Tc- $99 \mathrm{~m}$ sestamibi infusion at the $7^{\text {th }}$ minute, according to already established standards ${ }^{33-35}$. The scintigraphy began 30-60 minutes after the stress and 60 minutes after injection at rest, with a snack between the infusion and acquisition of images. The tomographic images (SPECT) were obtained with a large-field gamma camera, with 64 photomultipliers (GE Starcam, Milwaukee, Wisconsin, E.U.A.), high-resolution parallel collimator for low energy, with energetic peak centered at $140 \mathrm{keV}$ and with a $20 \%$ window, previously checked for uniformity of the detector and rotation center. The study consisted of 64 projections of 20 seconds each, in a $180^{\circ}$ arch, beginning in a RAO view of $45^{\circ}$, and ending in a left posterior oblique (LPO) view of $45^{\circ}$, with a 64 X64 matrix. Image processing involved reconstruction obtainning $6 \mathrm{~mm}$ thick tomographic slices at the short, horizontal and vertical long axes, and also semiquantitative analysis through polar maps.

The comparative study between the two methods of assessing myocardial ischemia was carried out in the patients who had undergone prior scintigraphy or who had undergone scintigraphy after cardiac catheterization, as a method necessary for evaluating the presence of ischemia, in order to define the therapeutical management. No patient underwent hemodynamic or cineangiocardiographic study or myocardial scintigraphy just to take part in the research protocol.

The study comprised only the LV segments assessed through contrast ventriculography in RAO view. They are: apical, anterolateral, anterobasal, diaphragmatic, and posterobasal segments. The septal segments analyzed by myocardial scintigraphy were excluded because this area was not analyzed in the projection used to obtain the contrast ventriculography.

The statistical analysis was performed through the Statistical Package for Social Science (SPSS) program, using multivariate analysis and logistic regression to reduce confounding factors.

\section{Results}

In the contrast ventriculographies of the 26 patients, the five already mentioned segments were compared in regard wall motion changes after the isosorbide mononitrate administration. In the apical segment, before drug administration, the results were: 1 normal, 6 hypokinetic and 19 dyskinetic segments. After drug administration, 15 were identified as normal segments, only 3 as hypokinetic, and 8 as dyskinetic $(\mathrm{p}=0.0003)$. In the anterobasal segment, before the isosorbide mononitrate administration, the results were: 13 normal, 12 hypokinetic, and 1 akinetic segment. After the drug administration, 24 segments were identified as normal and only one as hypokinetic, and the one that was akinetic prior to drug use, remained so $(\mathrm{p}=0.0033)$. In the posterobasal segment, before drug administration, the results were: 7 normal, 14 hypokinetic, and 5 akinetic segments. After drug use, 19 segments were normal, 2 hypokinetic, 1 dyskinetic, and 4 akinetic; among these segments, one that was first characterized as akinetic, turned into dyskinetic $(\mathrm{p}=0.0015)$. In the anterolateral segment, at basal conditions, the results were: 2 normal, 15 hypokinetic, 8 dyskinetic, and 1 akinetic segment. With the use of the drug, there were alterations: 20 normal, 3 hypokinetic, 2 dyskinetic, and 1 akinetic segment ( $\mathrm{p}=0.0001)$. In the diaphragmatic segment, prior to drug administration, the results were: 7 normal, 15 hypokinetic, 1 dyskinetic, and 3 akinetic. After drug administration, the results changed: 21 normal, 2 hypokinetic, and 3 akinetic segments $(\mathrm{p}=0.001)$ (table $\mathrm{I})$.

When compared with contrast ventriculography after drug administration, scintigraphy confirmed the same results. Among the segments analyzed from the 26 patients, 99 revealed normal motility in ventriculography and 110 presented ischemic characteristics in scintigraphy. The remaining segments that revealed evidence of necrosis in the contrast ventriculography comprised 11 hypokinetic, 11

\begin{tabular}{|c|c|c|c|c|c|c|c|c|c|c|c|c|c|c|c|c|}
\hline \multirow[t]{2}{*}{ Segment } & \multicolumn{2}{|c|}{ Normal } & \multicolumn{2}{|c|}{ Hypokinetic } & \multicolumn{2}{|c|}{ Dyskinetic } & \multicolumn{2}{|c|}{ Akinetic } & \multicolumn{2}{|c|}{ Normal } & \multicolumn{2}{|c|}{ Hypokinetic } & \multicolumn{2}{|c|}{ Dyskinetic } & \multicolumn{2}{|c|}{ Akinetic } \\
\hline & $\mathrm{N}$ & $\%$ & $\mathrm{~N}$ & $\%$ & $\mathrm{~N}$ & $\%$ & $\mathrm{~N}$ & $\%$ & $\mathrm{~N}$ & $\%$ & $\mathrm{~N}$ & $\%$ & $\mathrm{~N}$ & $\%$ & $\mathrm{~N}$ & $\%$ \\
\hline Apical & 1 & 3.8 & 6 & 23.1 & 19 & 73.1 & - & - & 15 & 57.7 & 3 & 11.5 & 8 & 30.8 & - & - \\
\hline Anterobasal & 13 & 50 & 12 & 46.2 & - & - & 1 & 3.8 & 24 & 92.3 & 1 & 3.8 & - & - & 1 & 3.8 \\
\hline Posterobasal & 7 & 26.9 & 14 & 53.8 & - & - & 5 & 19.2 & 19 & 73.1 & 2 & 7.7 & 1 & 3.8 & 4 & 15.4 \\
\hline Anterolateral & 2 & 7.7 & 15 & 57.7 & 8 & 30.8 & 1 & 3.8 & 20 & 76.9 & 3 & 11.5 & 2 & 7.7 & 1 & 3.8 \\
\hline Diaphragmatic & 7 & 26.9 & 15 & 57.7 & 1 & 3.8 & 3 & 11.5 & 21 & 80.8 & 2 & 7.7 & - & - & 3 & 11.5 \\
\hline
\end{tabular}


dyskinetic, and 8 akinetic, while in scintigraphy 18 segments also presented fibrosis $(\mathrm{p}=0.041$; Sensitivity $(\mathrm{Se})=81 \%$; Specificity $(\mathrm{Sp})=64.29 \%)$. When scintigraphy and ventriculography were compared specifically by each segment, the posterobasal segment presented statistically significant results. In regard to this segment, from the 19 cases identified as ischemic by ventriculography, 15 were confirmed by scintigraphy. Seven patients presented necrosis by ventriculography; seven patients also presented necrosis in scintigraphy $(\mathrm{p}=0.0012 ; \mathrm{Se}=73.68 \% ; \mathrm{Sp}=100 \%)$ (fig. 1).

The other variables studied also confirmed the efficacy of the drug. CFS in the period prior to drug administration showed a mean value of 0.8572 , which changed to 1.0612 after the drug administration ( $\mathrm{p}=0.0142$ ) (fig. 2 ). $\mathrm{EF}$ changed from a mean value of $48.82 \%$ to $53.04 \%$ after the end of the experiment in the 26 cases ( $\mathrm{p}=0.0462$ ) (fig. 3). ESV showed a mean value of 54.22 prior to medication; it decreased to 45.20 after the administration of the isosorbide mononitrate ( $\mathrm{p}=0.0031$ ) (fig. 4). EDV did not show a significant difference in regard to drug administration; its mean

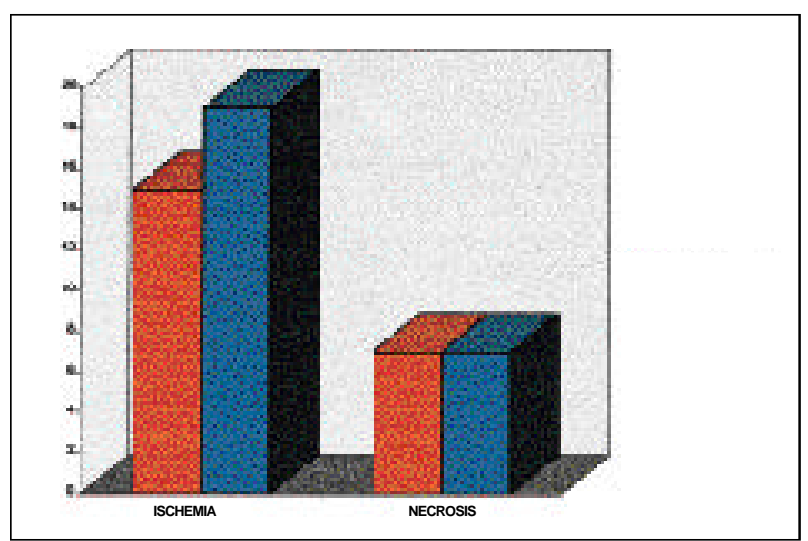

Fig. 1 - Result of the comparison of methods for the posterobasal segment. The equivalence between the methods (scintigraphy, in red, and contrast ventriculography, in blue) is demonstrated, before and after the use of isosorbide mononitrate, to identify viable ischemia or fibrosis (necrosis). Among the segments analyzed, the posterobasal segment had statistically significant values ( $\mathrm{p}=0.0012 ; \mathrm{Se}=73.668 \%$; $\mathrm{Sp}=100 \%$ ).

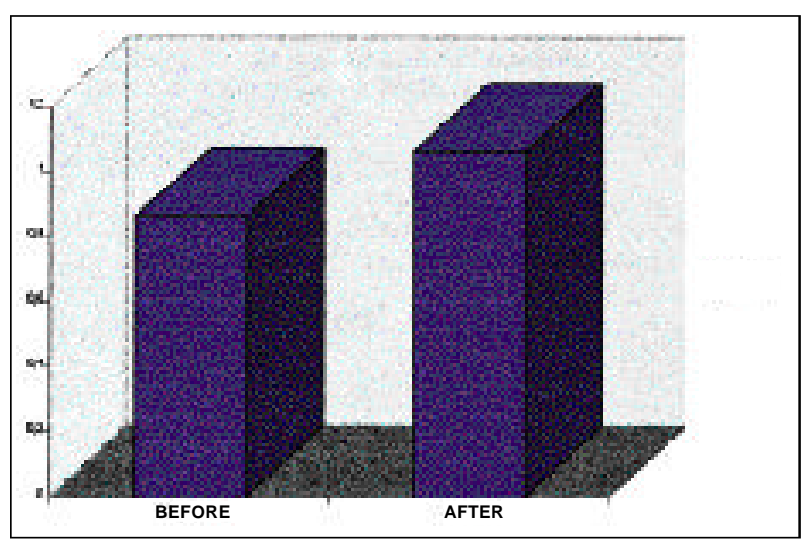

Fig. 2-Mean velocity of circumferential fiber shortening in relation to the use of the study drug. It shows the statistically significant variation in the velocity of circumferential fiber shortening, when compared before and after the use of isosorbide mononitrate $(\mathrm{p}=0.0142)$. value prior to drug administration was 106.89 , and after drug administration it was $100.46(\mathrm{p}=0.1014)$.

The values that characterize the percentage of the hemiaxes shortening in relation to systole and diastole were statistically significant at R2R5 and R3R4, but not at R1R6. The mean values of R2R5 in the 26 cases were 29.94 and 34.38 , before and after drug administration, respectively ( $\mathrm{p}=0.000)$. For R3R4, the values were 27.26 and 32.35, before and after drug administration, respectively $(\mathrm{p}=0.037)$ (fig. 5).

\section{Discussion}

The identification of myocardial ischemia plays a significant role in the choice of pharmacological or interventional therapeutical management. More than 200 years ago, prior to the appearance of the revascularization methods, nitrates were effectively used for the treatment of ischemic clinical manifestations ${ }^{36,37}$. With the technological conditions existing since the 1950 s, it was initially proved that nitrates reduced pre- and afterload and, consequently,

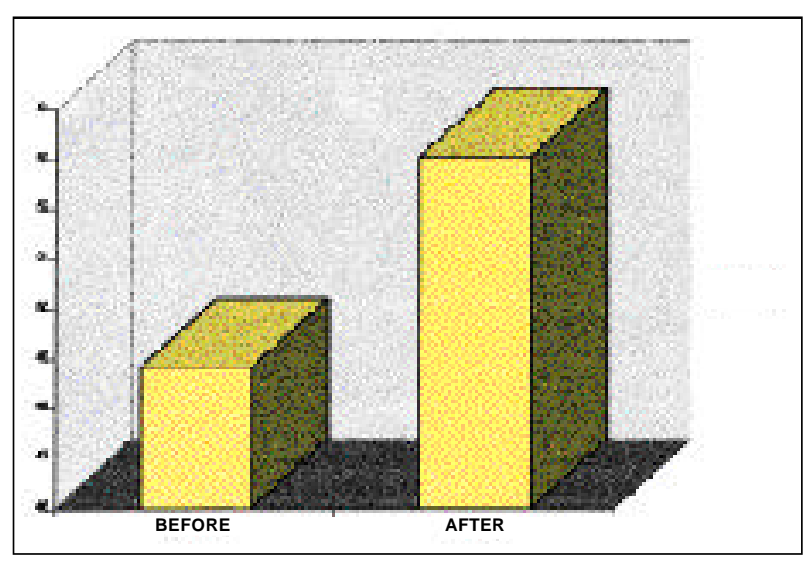

Fig. 3 - Mean ejection fraction in relation to the use of the study drug. It shows the statistically significant variation in the ejection fraction, when compared before and after the use of isosorbide mononitrate $(\mathrm{p}=0.0462)$.

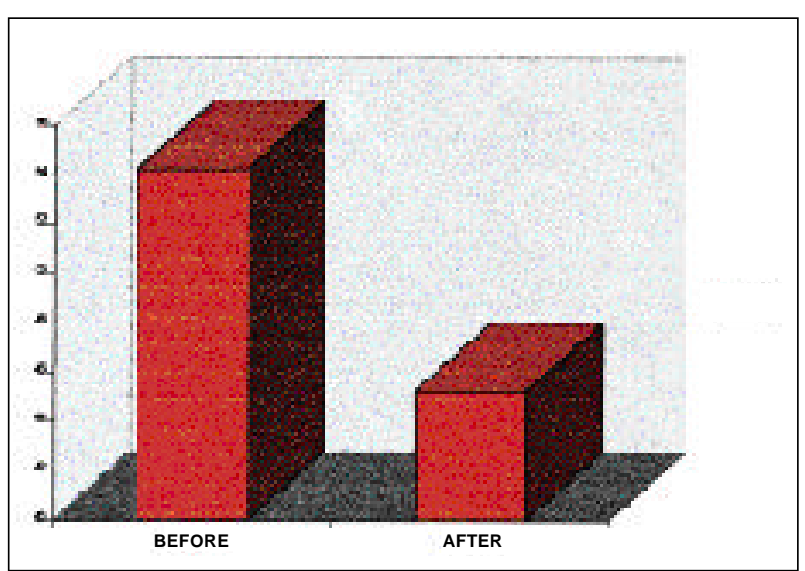

Fig. 4 - Variation in the end-systolic volume in relation to the use of the study drug. It shows the statistically significant variation in end-systolic volume, when compared before and after the use of isosorbide mononitrate $(\mathrm{p}=0.0031)$. 


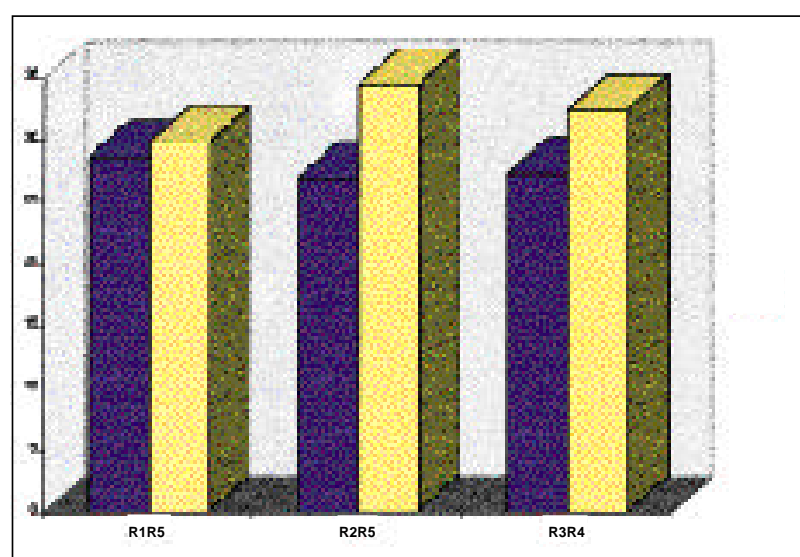

Fig. 5 - Percentage of shortening of the hemiaxes. It shows the statistically significant increase in the shortening of cardiac hemiaxes, which are determined in systole and diastole, after nitrate infusion (yellow) drug (R2R5 p=0.000 and R3R4 $\mathrm{p}=0.0037$ ).

the cardiac work, being responsible for the improvement of the patient's symptoms. Later, with new equipment, other more recent studies widened the knowledge of nitrate action mechanisms in myocardial ischemia. Among them, we distinguish their confirmed vasodilating action on the coronary arterial tree, their direct effect on flow distribution to ischemic areas and on the collateral coronary circulation $9,21,38,39$.

In the 1970s, with the need to identify the presence of myocardial ischemia, as a parameter for the indication of revascularization, nitroglycerin began to be used in hemodynamic laboratories, with the same purpose. In 1974, using two ventriculographies, one before and another after the use of nitroglycerin, Dove et $\mathrm{al}^{40}$ showed that the method allowed the differentiation between myocardial ischemic and fibrotic areas. This technique provided proof that the segments, whose motility improved after the use of nitrate, were also the ones that improved after myocardial revascularization ${ }^{38,39}$.

Our experience in the investigation of nitrate effects on circulation and on the heart dates from the 1970s. With the first studies, we had the opportunity to verify that nitroglycerin did not have the same effects on cardiac performance in the different forms of heart disease. Even though the drug caused similar effects on the pulmonary circulation, systemic circulation, and heart rate, either in normal individuals or in those with ischemic heart disease, valvular heart diseases or primary cardiomyopathies, it only improved LV performance in patients with ventricular dyssynergia due to coronary obstruction ${ }^{41}$. In other studies ${ }^{42,43}$, we showed that all nitrates, although having small differences in their pharmacodynamic properties, normalized wall motion of the hypokinetic segments, improved the majority of the dyskinetic segments, and did not alter the motility of the akinetic segments. Based on these findings, we started to use the method to choose the appropriate therapeutical management. Currently, due to the introduction of multiple catheter based myocardial revascularization procedures, the iden- tification of myocardial ischemia became a point of fundamental importance in the choice of the most adequate therapeutical management. The need for a better understanding of myocardial conditions in ischemic heart disease gained great support through the development of more efficient methods to evaluate myocardial conditions. Among them, we highlight perfusional myocardial thallium201 scintigraphy and Tc-99m sestamibi with SPECT and, more recently, the utilization of stress echocardiography, all very useful tools to evaluate the presence of myocardial ischemia $^{44-47}$. In 1995, Bisi et $\mathrm{al}^{48}$ introduced the nitrates to evaluate myocardial ischemia through perfusional myocardial scintigraphy with Tc-99m sestamibi. In this study, the authors found that the segments that improved the uptake after the administration of nitrates were those that showed an improvement regional wall motion after myocardial revascularization. Although these studies employed different equipment, they led to the same conclusions as Dove et $\mathrm{al}^{40}$ and Helfant et $\mathrm{al}^{49}$, in the $70 \mathrm{~s}$, and also to results similar to ours in the present study.

Contrast ventriculography identified, at basal conditions, 30 normal, 62 hypokinetic, 28 dyskinetic, and 14 akinetic segments. After isosorbide mononitrate administration, 99 segments were normal, and there were only 11 hypokinetic, 11 dyskinetic, and 13 akinetic segments. From the 14 akinetic segments, only one improved motility after nitrate use, while the others remained unaltered. The analysis of myocardial scintigraphy of the same areas showed that 110 segments had characteristics of ischemia and 18 of necrosis. These data confirmed the results obtained with the segments that improved motility after nitrate use.

The analysis of the assessment of LV performance showed that the hemiaxes R2R5 and R3R4 significantly shortened, and CFS and EF improved after nitrate use. In this present study we can state that nitrate use identified the myocardial segments that improved their motility, and these segments were identified by myocardial scintigraphy as ischemic myocardial segments. This does not allow us to suppose that left ventriculography with nitrate use will replace myocardial scintigraphy, because these are distinct methods of evaluation.

However, with the results obtained in the present study, considering the size of the sample and the methodology adopted, we conclude that using isosorbide mononitrate intravenously we can identify the presence of myocardial ischemia through contrast ventriculography, with the same efficiency observed with the myocardial perfusion scintigraphy.

This finding has significant practical consequences. It can speed the therapeutic decision making and reduce the number of to tests, which the patients have to undergo.

\section{Acknowledgments}

To the Fundação de Amparo à Pesquisa do Rio Grande do Sul - FAPERGS (Foundation of Research Support of Rio Grande do Sul). 


\section{References}

1. Tennant T, Wiggers CJ. Effect of coronary occlusion on myocardial contraction. Am J Physiol 1985; 112: 351-61

2. Ellis CG, Hensechke CL, Sandor T, et al. Time course of functional and biochemical recovery of myocardium salvaged by reperfusion. J Am Coll Cardiol 1987; 1: 1047-55.

3. Bolli R,Zhu W, Thornby JI, et al. Time course and determinants of recovery of function after reversible ischaemia in conscious dogs. Am J Physiol 1988; 254: 1102-11.

4. Preuss K, Garret JG, Brooks III, et al. Time course of recovery of stunned myocardium following variable periods of ischemia in conscious and anesthetized dogs. Am Heart J 1987; 114: 696-703.

5. Pasternak R, Braunwald E, Sobel BE. Acute myocardial infarction. In: Braunwald E - Heart Disease, 1992; 39: 1200-91

6. Tonchstone DA, Beler GA, Nygaard TW, et al. Effects of successful intravenous reperfusion therapy on regional myocardial function and geometry in humans: a tomography assessment using two-dimensional echocardiography. J Am Coll Cardiol 1989; 13: 1506-13.

7. Gruenzig GC, Senning A, Siegenthaler WE. Nonoperative dilatation of coronary artery stenosis: percutaneous transluminal coronary angioplasty. N Engl J Med 1979; 301: 61-8.

8. Welty FK, Mittleman MA, Healy RW, et al. Similar results of percutaneous transluminal coronary angioplasty for women and men with postmyocardial infarction ischemia. Am J Coll Cardiol 1994; 23: 35-9.

9. Wimbury MM. Redistribution of ventricular blood flow produced by nitroglycerin. Circ Res 1971(suppl.); 1: 28-9

10. Dove JT, Shah PM, Schreiner BF, et al. Effects of nitroglycerin on left ventricular wall motion in coronary artery disease. Circulation 1974; 49: 682-8.

11. Domesnil JG, Ritman EL, Davis SE, et al. Regional left ventricular wall dynamics before and after sublingual administration of nitroglycerin. Am J Cardiol 1975; 36: 419-21.

12. Manfroi WC, Freitas FM. Ação da nitroglicerina sobre a circulação e sobre a fração de ejeção do ventrículo esquerdo em pacientes com comprometimento anátomofuncional do miocárdio ventricular. Arq Bras Cardiol 1982; 39: 315-20.

13. Manfroi WC, Zago AJ, Raudales JC, et al. Identificação de isquemia miocárdica viável em pacientes com infarto do miocárdio pela análise das cineventriculografias obtidas antes e após o uso de mononitrato de isossorbitol por via venosa. Revista Brasileira de Cardiologia Invasiva 1995; 3: 50.

14. Amsterdam E. Assessment of methods to detect symptomatic and silent myocardial ischemia. Arq Bras Cardiol 1994; 63: 141-5.

15. Eitman D, Al-Aovar Z, Kanter HL, et al. Clinical outcome of studies with advanced coronary artery disease after viability studies with positron tomography. J Am Coll Cardiol 1992; 20: 559-65.

16. Dilsizian V, Bonow R. Current diagnostic techniques of assessing myocardial viability in patients with hibernating stunned myocardium. Circulation 1993; 87: 1-20.

17. Yamamoto K, Asada S, Masuyama T, et al. Myocardial hibernation in the infarcted region cannot be assessed from the presence of stress-induced ischemia: Usefulness of delayed image of exercise thallium-201 scintigraphy. Am Heart J 1993; 125: 33-40.

18. Camaro G, Ragosta M, Gimple LW, et al. Identification of viable myocardium with contrast echocardiography in patients with poor left ventricular systolic function caused by recent or remote myocardial infarction. Am J Cardiol 1995; 75: 215-9.

19. Garcia MJ, Neumann D, Go RT, et al. Comparison of persistent thallium perfusion defects by quantitative washout analysis with thallium reinjection in patients with coronary artery disease. Am J Cardiol 1994; 74: 977-81.

20. Salustri A, Elhendy A, Garyfallydis P, et al. Prediction of improvement of ventricular function after first acute myocardial infarction using low-dose dobutamine stress echocardiography. Am J Cardiol 1994; 74: 853-86.

21. Galli M, Marcassa C, Imparato A, et al. Effects of nitroglycerin by technetium-99m sestamibi tomo scintigraphy on resting regional myocardial hypoperfusion in stable patients with healed myocardial infarction. Am J Cardiol 1994; 74: 843-8.

22. Camarano G, Ragosta M, Gimple L, et al. Identification of viable myocardium with contrast echocardiography in patients with poor left ventricular systolic function caused by recent or remote myocardial infarction. Am J Cardiol 1995; 75: 215-19.

23. Salustri A, Garyfallydis P, Elhendy A, et al. T-wave normalization during dobutamine echocardiography for diagnosis of viable myocardium. Am J Cardiol 1995; 75: 505-07.

24. Galassi A, Centamore G, Fiscella A, et al. Comparison of rest-redistribution thallium-201 imaging and rejection after stress-redistribution for the assess- ment of myocardial viability in patients with left ventricular dysfunction secondary to coronary artery disease. Am J Cardiol 1995; 75: 436-42.

25. Carvalho PA, Holman DL, Piwnica-Worms D. Uptake and intention of hexakis (2-methhoxyisobutyl-isonitrile) technetium (I) in cultured chick myocardial cells. Mitochondrial and plasma membrane potential dependence. Circulation 1990; 82: 1826-38.

26. Manfroi WC, Zago AJ, Ribeiro JP, et al. Efeito agudo do mononitrato de isossorbitol sobre a circulação e isquemia miocárdica em pacientes com aterosclerose coronária. Arq Bras Cardiol 1995; 65: 11-15.

27. Sones FM, Shirey EK. Cinecoronary arteriography. Mod Concepts Cardiovasc Dis 1961; 2: 735-6.

28. Judkins MP. Selective coronary arteriography. A percutaneous transfemoral technique. Radiology 1967; 89: 815-24.

29. Gault JH. Angiography estimation of left ventricular volume. Cath Cardiovasc Diag 1975; 1: 7-14

30. Karliner JS, Gault JH, Ecker D, et al. Mean velocity of fiber shortening. Simplified left ventricular myocardial contractility. Circulation 1971; 44: 323-30.

31. Sesto M, Schwarz F. Regional myocardial function at rest and after rapid ventricular pacing in patients after myocardial revascularization by coronary bypass graft or by collateral vessels. Am J Cardiol 1979; 43: 920-28.

32. Herman MV, Heinke RA, Klein MD, Gorlin R. Localized disorders in myocardial contraction: Asynergy and its role in congestive heart failure. N Engl J Med 1967; 277: 222.

33. Li Qs, Solot G. Myocardial distribution of technetium-99m-methoxyisobutylisonitrile (SESTAMIBI). J Nucl Med 1990; 31: 1069-76.

34. Machal J. Technetium-99m-isonitrile: a perfusion or a viability agent? J Am Coll Cardiol 1989; 14: 1685-8.

35. Piwnica-Worms D, Kronaube JF, Chium L. Uptake and retention of hexakis (2methoxyisobutyl isonitrile) technetium (I) in cultured chick myocardial cells. Circulation 1990; 82: 1826-38.

36. Bruton PR. On the use of nitrite of amyl in angina pectoris. Lancet 1767; 2: 9.

37. Murrell W. Nitroglycerin as a remedy for angina pectoris. Lancet 1979; 81: 113-5.

38. Horwitz LD, Gorlin R, Taylor WJ, et al. Effects of nitroglycerin on regional myocardial blood flow in coronary artery disease. J Clin Invest 1971; 50: 1578-81.

39. Goldstein RE, Stinson EB, Scherer RP, et al. Intraoperative coronary collateral function in patients with coronary occlusive disease. Nitroglycerin responsiveness and angiographic correlation. Circulation 1974; 49: 298-308.

40. Dove JT, Shah PM, Schreiner BF. Effects of nitroglycerin on left ventricular wall motion in coronary artery disease. Circulation 1974; 49: 682-8.

41. Manfroi WC, Freitas FM. Ação da nitroglicerina sobre a circulação e sobre a fração de ejeção do ventrículo esquerdo em pacientes com comprometimento anátomofuncional do miocárdio ventricular. Arq Bras Cardiol 1982; 39: 315-20.

42. Vieira SR, Manfroi WC, Freitas FM, et al. Efeitos hemodinâmicos e cineangiocardiográficos do dinitrato de isossorbitol sublingual na cardiopatia isquêmica. Revista do HCPA 1985; 2: 39-44.

43. Manfroi WC, Kopp V, Vieira SMR, et al. Efeitos hemodinâmicos e cineangiocardiográficos do propatilnitrato na cardiopatia isquêmica sintomática. Arq Bras Cardiol 1987; 18: 147-51

44. Foster T, McNeill A, Salustri A, et al. Simultaneous dobutamine stress echocardiography and technetium- $99 \mathrm{~m}$ isonitrile single-photon emission computed tomography in patients with suspected coronary artery disease. J Am Coll Cardiol 1993; 21: 1591-6.

45. American Society of Echocardiography Committee on Standards, Subcommittee on Quantitation of Two-Dimensional Echocardiograms. In: Schiller NB, Shah PM, Crawford M, et al. Recommendations for quantitation of the left ventricle by two-dimensional echocardiography. J Am Soc Echocardiogr 1989; 2: 358-67.

46. Marzullo P, Parodi O, Picano E, et al. Imaging of myocardial viability: a head-tohead comparison among nuclear, echocardiographic and angiographic techniques. Am J Cardiac Imaging 1993; 71: 143-51.

47. Schafers M, Matheja P, Hasfeld M, et al. The clinical impact of thallium-201 reinjection for the detection of myocardial hibernation. European J Nuclear Med 1996; 23: 407-13.

48. Bisi G, Sciagra R, Santoro GM, et al. Technetium-99m-sestamibi imaging with nitrate infusion to detect viable hibernating myocardium and predict postrevascularization recovery. J Nucl Med 1995; 36: 1994-2000.

49. Helfant RH, Pine R, Meister SG, et al. Nitroglycerin to unmask reversible asynergy. Correlation with post-coronary bypass ventriculography. Circulation 1974; 50: 108 